\title{
Calila e Dimna como instrumento de memoria alfonsí y las narrativas epigráficas en la Estoria de España ${ }^{1}$
}

\author{
Calila e Dimna as an Alfonsine memory tool and epigraphic narratives in the \\ Estoria de España
}

Ulrike Becker

ulbecker@uni-bonn.de

Rheinische Friedrich-Wilhelms-Universität Bonn, Alemania

Recepción: 23 Abril 2021

Aprobación: 06 Agosto 2021

Publicación: 01 Noviembre 2021

Cita sugerida: Becker, U( 2021) . Calila e Dimna como instrumento de memoria alfonsí y las narrativas epigráficas en la Estoria de España. Olivar, 21(34), e108. https://doi.org/10.24215/18524478e108
Resumen: Calila e Dimna -en su calidad de espejo de príncipes de origen oriental y primera traducción de un texto narrativo en prosa por orden del infante Alfonso (1251)- proporciona un fondo de estrategias de construcción de la memoria regia. Partiendo de manera paradigmática del capítulo "Del fijo del rey e del fidalgo e de sus compañeros", y teniendo en cuenta su raíz transcultural, es instructivo relacionar los métodos respectivos descritos en Calila e Dimna con los procedimientos de los escritos historiográficos encargados por Alfonso más tarde como rey, en particular aquellos en la Estoria de España. Ambos textos contienen secuencias narrativas que reproducen inscripciones ficticias. Estas inscripciones, su puesta en escena y las narrativas de poder inherentes se analizarán en este estudio con respecto a la memoria política y a las implicaciones en la cultura política del reinado alfonsí. Las medidas mediáticas destinadas a conservar la memoria del monarca a través de la epigráfica, que abarcan desde aspectos genealógicos hasta monumentos funerarios, suelen servir, asimismo, como legitimación del señorío.

Palabras clave: Alfonso X, Calila e Dimna, Estoria de España, Epigrafía, Lugar de memoria.

Abstract: Calila and Dimna -as a mirror of princes of oriental origin and the first translation of a narrative prose text by order of Alfonso (1251) still being the heir of throne- provides a fund of strategies for the construction of royal memory. Starting in a paradigmatic way from the chapter "Del fijo del rey e del fidalgo e de sus compañeros" (The prince and his companions), and considering its transcultural origin, it is instructive to relate the respective methods described in Calila and Dimna to the procedures of the historiographic writings commissioned by Alfonso later as king, in particular those in the Estoria de España. Both texts contain narrative sequences that reproduce fictitious inscriptions. These inscriptions, their staging and the inherent narratives of dominion will be analyzed in this study with respect to political memory and the implications for the political culture of the Alfonsine reign. The media measures aimed at preserving the memory of the monarch through epigraphy, ranging from genealogical aspects to funeral monuments, often also serve to legitimize the kingship.

Keywords: Alfonso X, Calila and Dimna, Estoria de España, Epigraphy, Spaces of memory. 
En 1251 el infante Alfonso mandó traducir Calila e Dimna ${ }^{2}$ - un espejo de príncipes de origen oriental- del árabe al castellano. Siguiendo la estructura imbricada de las muñecas rusas y del maqāmāt, la tradición árabe de contar historias, ${ }^{3}$ los ejemplos y las fábulas de animales se insertan en un marco narrativo formado por un diálogo didáctico entre un rey y su consejero, un filósofo. Los diálogos abarcan temas como los requisitos para ser un buen gobernante, la legitimación del poder y la aseguración del poder en el futuro. Se puede asumir que Alfonso entendía este espejo de príncipes como un manual de conocimiento político práctico y del "buen" gobierno. También con respecto a los aspectos de la memoria, el texto contribuye a crear un contexto estratégico-discursivo. Como Aleida Assmann señala en su obra seminal de teorías de memoria, Cultural Memory and Western Civilization, ${ }^{4}$ con respecto a las formas de la memoria, se puede observar una alianza típica entre el poder y la memoria oficial-política destinada a la legitimación de este a través de conocimientos históricos detallados, preferentemente en forma de genealogías (2013, p. 128). A este respecto, es instructivo relacionar los métodos estratégicos descritos en Calila e Dimna con los procedimientos de los escritos historiográficos encargados posteriormente por el rey Alfonso X, en particular los que vertebran la Estoria de España, que Inés Fernández-Ordoñez categoriza explícitamente también como espejo de príncipes: “Aunque la Estoria alfonsí cumple el viejo papel de magister vitae, es sobre todo magister principum” (2009, p. 40). Ambos textos, tanto el Calila como la Estoria, contienen secuencias narrativas en las cuales se reproducen inscripciones ficticias. Estas inscripciones, su puesta en escena y las narrativas de poder inherentes a ellas se analizarán en el presente estudio con respecto a la memoria política y sus implicaciones en la cultura política del reinado alfonsí. Ambos textos tienen en común el uso de la lengua vernácula, a saber, cada uno como el primero de su género. Por consiguiente, se enfocará igualmente en la importancia tanto del léxico como de la retórica en las inscripciones. El punto de partida de este estudio en Calila e Dimna es el capítulo "Del fijo del rey e del fidalgo e de sus compañero"" (Döhla, 2009, pp. 440-457), que fue insertado en Kalïla wa-Dimna (la versión árabe preliminar) por el traductor Ibn al-Muqaffa. En este capítulo, la inscripción memorialística tiene un significado destacado, pues plantea una conexión con el contexto político concreto del gobierno de Alfonso y sugiere una adaptación de los instrumentos estratégicos esbozados en los textos estudiados a su propia práctica de gobierno, especialmente con respecto a los aspectos fundamentales de la memoria política, tales como las narrativas señoriales y el significado del prinicipio genealógico, porque "power needs origins" (Assmann, 2013, p. 128). Ante este estado de cosas, el presente estudio se propone analizar en qué medida determinados instrumentos de la memoria operantes en Calila e Dimna contribuyen a abrir una perspectiva transcultural al afán de Alfonso X por configurar su reinado y la cultura de su corte.

Por consiguiente, después de un breve esbozo del contenido del capítulo "Del fijo del rey e del fidalgo e de sus compañeros", sigue en el siguiente apartado de este estudio (Calila e Dimna: "el enxemplo del rey que fizo escrivir sobre la puerta de su cibdad") el análisis de las inscripciones ficticias en Calila e Dimna para definir los instrumentos destinados a la construcción memorialística, con el fin de rastrearlos posteriormente de manera paradigmática tanto en la Estoria de España como en la realidad histórica del reinado de Alfonso X. Para ello conviene centrarse en la importancia de Toledo y Sevilla, tanto como localidades (históricas) como en términos de la narrativa dinástica, es decir, con respecto a los aspectos relativos a esta en Calila $e$ Dimna. Los mismos criterios se aplican en la segunda parte de este estudio (Inscripciones necrológicas: "Aquí yaze el rey”), ${ }^{6}$ que se enfocará en la legitimación de gobernantes. De nuevo se volverá a tomar como punto de partida Calila e Dimna, con vistas al análisis de la Estoria de España y la práctica conmemorativa alfonsí. El enfoque analítico reside en la presentación de unas relaciones -basadas de manera paradigmática en un 
relato- entre Calila e Dimna como texto prototípico del contexto histórico-cultural (espejo de príncipes, literatura sapiencial de origen oriental) y el proyecto cultural-político alfonsí. Estas relaciones permiten rastrear el ámbito de algunas de las ambiciones concretas de Alfonso.

Con respecto a la terminología cabe señalar que el hecho de focalizarse en las inscripciones ficticias de los textos narrativos implica diferentes niveles de análisis, a saber, lo que se recuerda, quién recuerda (el agente) y qué intenciones determinan el relato memorialístico. Lo mismo ocurre con los objetos descritos tanto en términos de contenido dentro del texto (es decir, en las secuencias narrativas en Calila e Dimna o en la Estoria de España), o en relación con el marco narrativo como en Calila e Dimna, así como con respecto a la práctica memoralística alfonsí. En este sentido, los términos "memoria", "recuerdo", "reminiscencia” y "rememoración” según Paul Ricoeur no se consideran pertinentes y aptos en sus estrictas definiciones para el propósito de este estudio, pues se basan en su análisis filosófico y semántico de la diferenciación aristotélica entre "mnēmē" y "anamnēsis" y de los conceptos asociados (Ricoeur, 2003, p. 36s.). ${ }^{7}$ Por lo tanto, estos términos se emplearán en un sentido pragmático.

\section{CALILA E DIMNA: "EL ENXEMPLO DEL REY QUE FIZO ESCRIVIR SOBRE LA PUERTA DE SU CIBDAD"8}

Según la estructura didáctica de Calila e Dimna, el tema de cada capítulo se señala en la pregunta inicial del gobernante, que luego es contestada por el filósofo en forma de ejemplos, tal como lo ilustra el capítulo "Del fijo del rey e del fidalgo e de sus compañeros" (Döhla, 2009, pp. 440-457). Este capítulo se abre con un diálogo-marco que plantea el tema de la ventura como designio divino que determina un destino individual en la vida terrenal. Antes de entrar con más detalle en su diseño narratológico y temático, daremos un breve esbozo del contenido del capítulo. Después de la muerte de un rey, el hijo destinado a ser su sucesor es forzado por su hermano a huir del reino. En su camino se encuentra con los hijos de un comerciante, un noble y un obrero. Los cuatro se juntan y deciden que uno tras otro deberán contribuir al mantenimiento del grupo a su manera. El hijo del rey, que es el último responsable, confía en la providencia de Dios. La llegada del grupo a una ciudad desconocida en otro reino coincide con la procesión fúnebre del rey local (que no es el padre del protagonista). El "hijo del rey" se queda sentado al borde de un pozo cerca de la puerta de la ciudad. Su comportamiento distraído, que no corresponde a la actitud de respeto esperada en homenaje al rey muerto, es percibido como una afrenta, lo cual se convierte en el punto de inflexión de su destino. El protagonista es llevado ante el nuevo rey para explicar el motivo de su falta de respeto y expresa así su pena a causa de la pérdida de su propio trono. El nuevo monarca, satisfecho con su explicación, le da a su hija como esposa y le apoya por medio de tropas y un equipaje magnífico, de modo que el protagonista logra tomar el poder de su propio reino sin necesidad de combatir a su hermano. Como primera acción después de la gloriosa conquista del trono, el rey manda hacer la inscripción que determina la estructura de la misma historia en Calila e Dimna. A continuación, convoca a sus antiguos compañeros de viaje y vuelve a resumir el curso de los acontecimientos. Luego reúne a todos los "grandes omnes de su regno, e sus cabdillos e alcalles e religiosos" (Döhla, 2009, A, p. 454) y da un breve discurso, seguido de otro de un "ricoome que fazié vida religioso" (Döhla, 2009, B, p. 454), lo que concluye tanto la legitimación del rey como el capítulo.

La importancia central de la inscripción ya mencionada como elemento estructurador de la historia y a nivel de contenido como medida política se revela narratológicamente por su ubicación destacada: esta se encuentra directamente al principio del capítulo en el contexto del contenido didáctico en el marco de la trama y, a la vez, desencadena la sesión de enseñanza del rey por parte del filósofo. Tres veces se repite explícitamente el proceso de hacer una inscripción:

E esto semeja al exemplo del rey que escrivió sobre la puerta de la cibdat suya que el buen entendimiento e la lavor e la hemencia e la arte en este mundo todo es en poder de la ventura. Dixo el Rey: “¿Cómo fue eso? ¿E por qué escrivió el Rey 
sobre la puerta de su cibdat eso?" Dixo el filósofo: “Dizen que esta fue la razón por que lo fizo escrivir, señor: así acaecio que cuatro mancebos se ayuntaron por un camino; (...).” (Döhla, 2009, B, p. 441)

Desde la introducción del ejemplo, la triple repetición sirve para crear una cierta tensión y focalizar lo esencial: la realización de una epigrafía. Más tarde y otra vez, en el núcleo de la narración, la inscripción en sí, es decir, la reproducción del texto mismo de la inscripción de manera detallada, ocupa un lugar central en el capítulo. En ambos casos (marco de la trama y ejemplo) se presenta la colocación de la inscripción sobre la puerta de una ciudad en propiedad del rey. Este hecho refleja la enorme relevancia del urbanismo, tanto en el contexto árabe original como en la época de Alfonso. ${ }^{9} \mathrm{Al}$ mismo tiempo subraya la función memorialística de este lugar a nivel ficcional: la puerta de la ciudad es un céntrico lugar de tránsito, todo el que entra en la ciudad tiene la inscripción ante sus ojos. Inscripciones como esta son visibles en el espacio "público” y documentan un hecho de manera duradera, monumentalizada. Esta visibilidad favorece la puesta en escena de la narrativa señorial. Asimismo, la inscripción, en combinación con las repeticiones retóricas y la localización urbana, construye, en el marco de este espejo de príncipes, un lugar de memoria avant la lettre según Pierre Nora: “La mémoire s'enracine dans le concret, dans l'espace, le geste, l'image et l'objet" (Nora, 1992, p. XIX). ${ }^{10}$ Por consiguiente, la estructura reiterativa y redundante atrae el interés por el contenido de la inscripción. Una secuencia particular del relato aquí mencionado de Calila e Dimna se dedica a la inscripción en la cual la narrativa legitimadora señorial es descrita detalladamente a pesar de su carácter ficticio:

Et este rey fizo escrivir sobre la puerta de la cibdat: "El lazerio de un ome que faga por sus manos en un día, fázele ganar que
coma él e tres compañeros por un dia. Et el buen enseñamiento e su linaje e su fermosura fázele ganar amor de los omes e
fázele perder señeridat, maguer sea en estraño lugar fuera de su tierra, et fázele ganar en un día cien marevedís. Et la invisidat
e la hemencia e la agudeza e entremetimiento faze ganar al ome en un día mill marevedís. Et encomendarse a Dios e meter su
fazienda en sus manos e atender su juizio, faze al rey que perdió su reino, fázelo cobrar e tornarlo en mejor estado que nunca
fuese. Que todas las cosas d'este mundo en el juizio de Dios son e por la ventura, así que ninguna cosa que Dios criase non ha
poder de mudarse un paso nin puede fazer cosa sin la voluntad de Dios et por lo que d'Él le es prometido e juzgado. Et todas
las cosas en Su poderío son, e Él las mantiene, así que ome non sabe como las Él ordena e las firma”. (Döhla, 2009, B, p. 452s.)

Esta inscripción asegura una transición de poder en la sucesión dinástica a través de una narrativa concreta. Tres aspectos son elementales: la fijación de un status quo - "que ninguna cosa que Dios criase non ha poder de mudarse un paso" (Döhla, 2009, B, p. 452) - cuyo mensaje ya está asegurado a manera de sentencia inmutable al comienzo del ejemplo: "Ninguno non puede por arte nin por seso desviar lo que Dios le judgó e prometió de antes” (Döhla, 2009, A, p. 441). Así, por un lado, el tiempo, a través de los aspectos de la tradición y de la continuidad y, por otro lado, Dios como garante, figuran como razones centrales de legitimidad. Con vistas al futuro, la inscripción actúa como una advertencia contra cualquier cambio. Además sirve de explicación a las circunstancias anteriores, constituyendo, en este caso, una narrativa de mejora -el segundo aspecto- en un contexto religioso: "Et encomendarse a Dios e meter su fazienda en sus manos e atender su juizio, faze al rey que perdió su reino, fázelo cobrar e tornarlo en mejor estado que nunca fuese." (Döhla, 2009, B, p. 452). El dominio "extranjero" temporal se explica, se supera y se absorbe en la propia narrativa. El tercer aspecto, y el más importante, es la legitimación. En el presente relato, el proceso de legitimación finaliza después de la secuencia narrativa de la inscripción mediante el discurso de un hombre religioso (Döhla, 2009, B, p. 454). Este señala que la idoneidad personal del hijo del rey radica en su confianza en la divina providencia entendida como "merced" de Dios, volviendo así sobre el texto de la inscripción: "Et hanos Dios fecho merced en quete nos dio por rey en vez del que murió" (Döhla, 2009, A, p. 455). Esta "merced” implica para el rey que "Derecho es de reinar" (Döhla, 2009, A, p. 455), privilegio fundamentado tanto por parte del rey, a quien Dios le otorga saber, como por parte de Dios, quien destina a este rey a ser sucesor del difunto. Este argumento "divino", al relacionar el pasado con el presente, es una prueba indudable de la legitimidad del monarca. Posteriormente, el rey convoca a sus antiguos compañeros de viaje y vuelve a relatar la narrativa tal y como está en la inscripción, consolidándola aún más. Se confirma así la función testimonial y demostrativa de la inscripción que, con frases casi doxológicas, sirve para legitimar al heredero legítimo al trono a través de 
la narración de acontecimientos históricos y con referencia a la genealogía. Igualmente, la inscripción sirve para asegurar el futuro.

Además de la función pragmática que se puede detectar a través de la visualización y la repetición de la inscripción a nivel narrativo, tanto el lenguaje como la semántica poseen un eminente papel político. En este contexto conviene señalar la importancia de la epigrafía árabe para la realidad política en la época histórica de la creación del Kalìla wa-Dimna:

el contenido textual de las inscripciones tiene asimismo una importancia incuestionable. (...) estos textos, redactados en las cancillerías del Estado, ofrecen una abundante información sobre la concepción que dicho Estado tenía de sí mismo y sobre la forma en que quería que se le viese, (...). En otras palabras, el poder establecido utilizaba y controlaba los textos y el diseño de los epígrafes oficiales con fines eminentemente propagandísticos. (Martínez Núñez, 1997, p. 416)

Además de las funciones de las inscripciones, también resulta significativo el establecimiento del árabe como lengua común en interés de la práctica política. Esta función también la cumplió Kalìla wa-Dimna como espejo de príncipes y primer texto ficcional árabe en prosa, siendo, además, uno de los primeros libros árabes que se publicaron antes de la revolución del libro en el siglo IX (Gründler, 2018, p. 67s.) Por lo tanto, este contexto también se aplica a la inscripción ficticia original en árabe, que luego se tradujo al castellano en Calila e Dimna. Puesto que Calila e Dimna es la primera traducción de un texto narrativo en prosa del árabe al castellano encargada por Alfonso, la semántica castellana, es decir el léxico elegido (linaje, enseñamiento, seso, acuerdo, saber, tornar en mejor estado, merced), es también decisiva, pues los términos de las calificaciones legitimadoras en la monarquía alfonsina se solidifican semánticamente a través de esta misma traducción al castellano. La inscripción ficticia y los términos castellanos utilizados en ella corresponden al estatus político de la epigrafía árabe. Sin embargo, el traslado de los correspondientes instrumentos de memoria de una cultura a otra conlleva una resemantización, es decir, según el concepto de "double movement" (Burke, 2009, p. 93), se produce una descontextualización y recontextualización en el curso de la adaptación al contexto histórico del reinado de Alfonso. Las inscripciones descritas en Calila e Dimna se prestan a la transmisión de mensajes como, en este caso, la narrativa señorial concreta en lugares que convierten la inscripción, la narrativa y los lugares mismos en lugares de memoria. En palabras de Pierre Nora: "Ils sont lieux, en effet, dans les trois sens du mot, matériel, symbolique et fonctionnel, mais simultanément, à degrés seulement divers." (1992, p. XXXIV).

\section{LA ESTORIA DE ESPAÑA}

Para Alfonso esta práctica memorial resulta ser importante, pues en su Estoria de España se aplica a personajes históricos o mitológicos y a ciudades con relevancia histórica. Además, a diferencia de las obras historiográficas anteriores, la crónica no fue escrita por un clérigo (como el Chronicon Mundi, encargado por la abuela de Alfonso, Berenguela, a Lucas de Tuy, canónigo de San Isidoro de León, o la Historia de Rebus Hispaniae, encargada por Fernando III el Santo, su padre, a Rodrigo Jiménez de Rada, arzobispo de Toledo), sino que fue creada en el taller alfonsí bajo la égida directa y la colaboración del rey. De nuevo, los aspectos semánticos son elementales, teniendo en cuenta que la Estoria de España fue la primera crónica redactada en castellano. El procedimiento corresponde con la intención política de utilizar el castellano como instrumento de cohesión tanto política como social (Fernández Gallardo, 2004, p. 81). Las narraciones de la restauración de Toledo y de la fundación de Sevilla están predestinadas a un análisis de las inscripciones que a estas se refieren. Según las estrategias explayadas a propósito del relato "Del fijo del rey e del fidalgo e de sus compañeros" el foco de interés será la pragmática memoralística de Alfonso con respecto a aspectos tanto funcionales como semánticos. 


\section{TOLEDO: "E PUSO EPITAFIOS SOBRE LAS PUERTAS DE LA CIBDAD"11}

La descripción de Toledo en la época del rey Wamba (siglo VII) es particularmente llamativa en la Estoria de España. Después de la narración del regreso de Wamba a Toledo tras sofocar una rebelión, sigue un capítulo aparte, cuyo título formula directamente nuestro punto principal: "De cómo el rey Bamba renovó los muros de Toledo. e puso epitafios sobre las puertas de la cibdad.” (E1, 182v). Desde un punto de vista estructural, estos epitafios ocupan un lugar preponderante en la Estoria, en concordancia con el procedimiento identificado en Calila e Dimna. A diferencia de sus predecesoras, la Estoria de España se distingue especialmente por su innovador principio estructural, que, por ejemplo, establece epígrafes típicos para la introducción de determinados párrafos temáticos (Fernández Gallardo, 2004, p. 102). Además, y, más allá del hecho de que tanto la inscripción como sus colocaciones son elementos centrales del capítulo, hay una repetición en la secuencia narrativa misma con vistas a Wamba:

E puso sobre las puertas por noblezas piedras mármoles llanas en que fizo escrivir viessos que son mucho apuestos e bien
dictados en latín e en gramátiga. E por ventura non paracen tan bien en el lenguaje, ca se non afieren tan bien las palabras. E
los viesos son estos: Erexit factore Deo Rex in clitus urbem. Vamba sue celebrem; portendens gentis honoren. E quieren dezir en
lenguage de Castiella desta guisa: "El noble rey Bamba alcó e mejoró la cibdad de Toledo con ayuda de Dios pora acrecentar
la onra e la nombradía de su yente". Otrossi fizo escrivir en seños mármoles estos otros viessos e ponerlos en las torres de
las puertas de la cibdad en aquellos que eran más acerca de algunas eglesias por onra de los santos mártires cuyas eran las
vocaciones: Vos, Domini sancti, quorum hicpresencia fulget, hanc urbem eplebem solito salvatefavorem. E quieren dezir d'esta
guisa en el lenguage de Castiella: "Vos, santos de Nuestro Señor que sodes onrados en este logar; salvad e guardad este (este)
pueblo e esta cibdad por el poder que avedes. (E1, 182v)

Las analogías con las estructuras e intenciones presentadas en Calila e Dimna son evidentes, sobre todo en lo que concierne a las repeticiones retóricas (más allá de la relación entre encabezamiento y contenido de la secuencia). Además, son especialmente interesantes las reflexiones sobre la adecuación de la semántica de la inscripción latina ("E por ventura non paracen tan bien en el lenguaje, ca se non afieren tan bien las palabras”, E1, 182v). Las traducciones adjuntas al castellano resultan ser instructivas con vistas a su léxico, que es similar al utilizado en Calila e Dimna. Pero también en términos de colocación (sobre las puertas) y contenido se pueden encontrar similitudes. La ciudad como sitio central de memoria y el foco en la visualización van acompañados de una narrativa señorial correspondiente: en lo referente al contenido, el aspecto del mejoramiento resulta ser igualmente significativo, tanto en el contexto narrativo ("mejorar su tierra", "renovo", "muy buena obra") como, sobre todo, en la inscripción, "alcó e meioró la cibdad" (E1, 182v). El segundo aspecto de la narrativa de poder es el apoyo divino, "Con ayuda de Dios" (E1, 182v). El carácter testimonial de las inscripciones sirve para legitimar el dominio de Wamba mediante el recuerdo de hechos históricos. En este contexto, la narrativa de mejora es al mismo tiempo un eslabón que se referirá posteriormente a la restauración del orden político después de un momento crucial de su reinado. Ya que tanto la puesta en escena como la semántica de la traducción de las inscripciones tienen su origen en el taller alfonsí, se pueden sacar conclusiones relativas a ambos niveles. Fernández-Ordóñez resume: "El rey es, así, la figura central de la Estoria. Por los derechos que le da la linna, ha recibido el poder de Dios, y al encarnar el senario, se convierte, quiera o no, en alma de su pueblo, el cual no es más que una proyección de él y de su ejemplo" (2009, p. 44). La Estoria de España corresponde a la actitud fundamental de los reyes medievales que se sitúan en un proceso de transmisión memoralística que incluye la dimensión genealógica (Rodríguez López, 2011, p. 294). Conforme con ello, la conexión entre los hechos históricos y la genealogía también se plantea a nivel de la historiografía alfonsina, en el interés de una memoria funcional centrada en la legitimación regia. Las inscripciones narrativas constituyen por lo tanto una imagen in nuce de la intención memoralística alfonsina en su combinación de escritura y objeto material. Vuelve a manifestarse aquí la importancia de la semántica en relación con la concepción de la monarquía alfonsina. Cabe destacar que la formula "Deo Rex", rey por Dios, -como reza la inscripción de Wamba en la Estoria de España- junto con la 
merced divina explayada en Calila e Dimna corresponde, además, al concepto del rey como vicario de Dios que se encuentra de manera explícita en las Siete Partidas (Partida II, Tít. 1. Ley 1, ed. 1807, p. 4).

Volviendo a las inscripciones en Toledo, en el interés de la memoria funcional con vistas a una narrativa diseñada para ser recordada, el siguiente episodio resulta sumamente revelador. En efecto, en 1259 Alfonso actúa en Toledo según este mismo modelo, con ocasión de la restauración de un puente: "Buen ejemplo de la utilización del espacio urbano para difundir mensajes de interés para el poder viene dado por el monumentum restaurationis que Alfonso X ordenó situar en el puente de Alcántara de Toledo, recordando la labor regia”. ${ }^{2}$ Esta inscripción contiene, en primer lugar, la narración de la restauración y, en segundo lugar, la referencia al anterior dominio moro, superado e inscrito de esta manera como victoria en la historia de Alfonso. Sigue la mención de la dinastía propia en la inscripción ("Fijo del noble rey don Fernando e de la reína doña Beatriz") junto con las fechas (Santiago Fernández, p. 524, n. 15). La colocación y la extensión de la inscripción también resultan reveladoras: "veintinueve líneas de caracteres góticos en relieves de la lápida situada sobre la puerta de la torre de entrada al puente, el único acceso a la ciudad, a través del Tajo, hasta la Reconquista." (Cómez Ramos, 2010/2011, p. 56). La protección de la propia epigrafía oficial en su versión original es asegurada por las Siete Partidas, en las que ciertos objetos muy concretos, y eventuales portadores de inscripciones, son calificados como "santos": "Santas cosas son llamados los muros et las puertas de las cibdades et de las villas” (Siete Partidas, Partida III, Tít. 28, Ley 15, ed. 1807, vol. 2, p. 715). Además, el derecho de sucesión se refiere explícitamente a este tipo de "cosas", excluyendo de cualquier legado testamentario, encima de "cosas sagradas" y de las "señaladamente de los reyes" (Siete Partidas, Partida VI, Tít. 9, Ley 13, ed. 1807, vol. 3 , p. 446), las siguientes: "las plazas et los exidos et las otras cosas que son comunales (...). Otrosí decimos que nin los mármoles, nin los pilares, nin las pilas, nin las puertas, nin madera nin ninguna de las cosas que son puestas et ayuntadas a las casas et a los otros edificios" (Siete Partidas, Partida VI, Tít. 9, Ley 13, ed. 1807, vol. 3, p. 447). Las Siete Partidas constituyen así una especie de protección más allá de la muerte del rey, al asegurar su memoria para el futuro. Una finalidad comparable a la que se observa al escribir las crónicas.

\section{SEVILla: "E LEYó EN Ellas QUE ALLí AVIÉ A SEER POBLADA LA GRAND CIBDAT"13}

En la Estoria de España, en el contexto de la historia fundacional de Sevilla, como en una carrera de relevos, una inscripción ficticia asume la función clave de la entrega del testigo a través de los tiempos entre Hércules y Julio César, antes de que la Sevilla contemporánea, una vez reconquistada por Fernando, se confirmara como metrópoli del reinado alfonsí. Además de repeticiones relativas a esta secuencia (la inscripción es visualmente prominente, como encabezamiento en mayúsculas pequeñas y repetida a su vez en el texto), se detecta una visualización narrativa suplementaria que refuerza la función de la inscripción. Al darse cuenta de que no va a ser él sino "omne onrado e más poderoso que él" (E1, 5r) quien fundará y poblará la ciudad, Hércules empieza a actuar: "Cuando esto oyó Hércules dixo que él farié remembrança por que cuando viniesse aquel que sopiesse el logar o avié de seer la cibdat” (E1, 5r). Para lograr esta finalidad memorialística se sirve de varios medios expresivos, al combinar arquitectura, escultura y escritura, cuyo mensaje es subrayado, además, por los gestos de la estatua antropomórfica:

E puso allí seis pilares de piedra muy grandes, e puso en somo una muy grand tabla de mármol escrita de grandes letras que dizién assí: "Aquí será poblada la grand cibdat". Y en somo puso una imagen de piedra, e tenié la una mano contra orient, e tenié escrito en la palma: "Fasta aquí llegó Hércules". Y el otra mano tenié contra yuso, mostrando con el dedo las letras de la tabla. $(\mathrm{E} 1,5 \mathrm{r})$

El contexto narrativo de la inscripción, mensaje escrito por Hércules destinado a César, constituye, por lo tanto, una comunicación a través del tiempo, dirigida hacia el futuro. Sin embargo, se observa un desfase en la realización de este aviso, que es revelador con respecto a los relatos de fundación, y, junto con ello, a la 
historiografía alfonsí y su manera de aplicar métodos pragmáticos de memoria política. El punto de partida de la narración es el siguiente:

E cuando [César] fue en aquel logar o primeramientre fue poblada la cibdat de Tálica, semejó 1 que no estava poblada en buen logar e fue buscar ó la assentasse de nuevo. E cuando fue a aquel logar o estavan los pilares sobre que pusiera Hércules la imagen, cató la tabla de mármol que yazié por pieças quebrada, e cuándo vio las letras fizolas ayuntar en uno e leyó en ellas que allí avié a seer poblada la grand cibdat. Estonce fizola mudar d'aquel logar e poblola allí o agora es e puso 1 nombre Íspalis. (E1, 5r)

La inscripción en la tablilla de mármol actúa como un momento inicial para el asentamiento y, al mismo tiempo, para las innovaciones compilatorias en la Estoria de España en contraste con las crónicas anteriores. Cabe subrayar que la Estoria de España no solamente se basa en precursores cristianos como la Historia de Rebus Hispaniae de Rodrigo Jiménez de Rada, en la que el propio Hércules funda Sevilla (FernándezOrdóñez, 2009, p. 125) y el Chronicon Mundi, sino que también incluye fuentes árabes (la Crónica del moro Rasis y algunas obras de historiadores y geógrafos hispano-árabes), que describen igualmente la construcción de la estatua y el mensaje para el futuro:

Con ello, la Estoria de España hace posible la inclusión de la tradición musulmana desechada por Rasis según la cual la fundación de Sevilla fue obra del caudillo romano, que la Estoria de España identifica con César, (...). Ese príncipe romano trasladó la ciudad de Itálica a la nueva capital, Sevilla, erigida en el lugar donde se halló el monumento hercúleo. (FernándezOrdoñez, 2009, p. 125s.)

Teniendo en cuenta que la intención de Alfonso es combinar "la idea de unos españoles primigenios con la de sucesivas invasiones que asolaron España” (Fernández Gallardo, 2004, p. 86) y, por otro lado, estando seguro de que el "reconocimiento de las virtudes del pueblo romano es incondicional" (Fernández Gallardo, 2004, p. 104) sobre todo con vistas al Fecho del Imperio, la creación de la Estoria de España "exigía la sutileza necesaria para hacer compatible la admiración por el legado romano (...) con la limitación de su contribución a la identidad hispana, cuyo aporte principal había de reservarse a los godos." (Fernández Gallardo, 2004, p. 104). En relación con el cambio de la figura fundadora de Sevilla de Hércules a César, la inscripción juega un papel central. Este manejo de la narración en la Estoria de España, tanto en lo referente al punto geográfico como a la comunicación en el tiempo, es interesante con respecto a las inscripciones, ya que se trata de un problema central de los aspectos memoriales-pragmáticos según Paul Ricoeur:

Este vínculo entre recuerdo y lugar plantea un difícil problema que adquirirá vigor en el punto de unión de la memoria y de la historia, el cual es también geografía. Este problema es el del grado de originariedad del fenómeno de datación, que tiene como paralelo el de localización. Datación y localización constituyen, a este respecto, fenómenos solidarios que muestran el vínculo inseparable entre la problemática del tiempo y la del espacio. (Ricoeur, 2003, p. 63).

Este problema de la ubicación espacio-temporal de la memoria se resuelve en la Estoria de España mediante la inscripción ficticia, la puesta en escena de la escritura sobre el objeto (la tablilla), de manera análoga a la inscripción ficticia que también sirve de instrumento de memoria en Calila e Dimna. En el caso de Sevilla, esta permite una adaptación de las fuentes y una reorientación de la perspectiva, dirigida así hacia un asentamiento, en vez de la destrucción descrita en las fuentes árabes: “"Historiar” o "historiografiar" la memoria es tener en cuenta que el pasado se puede reinterpretar" (Sanmartín, 2014, p. 43). En otras palabras, este tipo de escritura contiene un alto potencial para adaptar la memoria a la propia intención política, para usarla como política de propaganda. En este caso crea un vínculo concreto con los antepasados, con "los relatos míticos de Hércules -fundador de España-“ (Rucquoi, 1992, p. 79) y Julio César -Yülís al-Qaysar "que fue el primero en llamarse César" (Fernández-Ordoñez, 2009, p. 125s.). ${ }^{14}$ Jan Assmann (1992, p. 76) anota: "Vergangenheit, die zur fundierenden Geschichte verfestigt und verinnerlicht wird, ist Mythos, völlig unabhängig davon, ob sie fiktiv oder faktisch ist." ${ }^{15}$ Asimismo, el relato de la fundación de Sevilla también contiene una narrativa de mejora ("semejó l que no estava poblada en buen logar, e fue buscar ó la assentasse de nuevo", E1, 5r). De hecho, tras su reconquista a manos de Fernando, Sevilla juega un papel igualmente 
importante en la actualidad política, así como en la práctica del gobierno de Alfonso. Con respecto a los aspectos dinásticos de epitafios en sitios sepulcrales, las inscripciones asumen de igual manera una función principal como instrumento de memoria, lo cual se tratará brevemente en el siguiente apartado.

\section{INSCRIPCIONES NECROLÓGICAS: "AQUÍ YAZE EL REY"16}

Las genealogías y las prácticas de conmemoración cumplen una función esencial con motivo de la muerte de un gobernante, la legitimación del heredero al trono y la consiguiente transferencia de poder. En el relato "Del fijo del rey e del fidalgo e de sus compañeros", en Calila e Dimna, la falta de reverencia del infante expulsado por su hermano, "asentado en los poyos de la puer[ta de la] cibdat" (Döhla, 2009, A, p. 447s.) ante el cortejo fúnebre del rey local muerto, representa el punto de inflexión de su destino: "et preguntole un duque e díxole: "¿Quién eres, o por [qué te a] sentaste aquí e non te moviste por el duelo del Rey, cuando pa[só por] aquí??"” (Döhla, 2009, A, p. 448). El duque informa al nuevo rey de esta grave ofensa, y este ordena llevarlo a la corte. El elemento central del episodio es la deficiente legitimación del nuevo rey, que resulta de la reverencia negada al rey muerto, su antecesor. Este déficit se basa en la importancia del vínculo genealógico, es decir, la reivindicación de la legitimidad del sucesor que resulta de la continuidad dinástica. Volviendo sobre el origen árabe y los tiempos de Ibn al-Muqaffa al inicio del califato abasí (siglo VIII), cabe subrayar que en el islam se crean unas características culturales específicas: según la tradición de Mahoma, se prohíbe la construcción de monumentos fúnebres y hasta una mera señalización o inscripción (Pahlitzsch, 2005, p. 72). Bajo lo aquí planteado -el aspecto prospectivo y funcional de la memoria dirigida hacia la legitimación, es decir, el factor político-, conviene referirse a Drews, según el cual ni siquiera los califas abasíes necesitaban expresar públicamente su legitimidad dinástica mediante edificios funerarios (2014, p. 250). No reciben su legitimidad a través de la conmemoración de los califas individuales, sino mediante la vinculación programática, es decir, la conmemoración de los comienzos dinásticos que se remonta al mismo profeta, lazo que constituye su capital simbólico esencial. ${ }^{17} \mathrm{El}$ lugar principal de recuerdo fue, por lo tanto, el formato de "texto" en el que se codificó el capital dinástico ${ }^{18}$ (Drews, 2014, p. 256). Teniendo en cuenta las peculiaridades transculturales y el significado del recuerdo dinástico en Calila e Dimna como en la Estoria de España es instructivo considerar qué papel tienen necrologías o inscripciones conmemorativas en la Estoria de España con respecto a las ya mencionadas ciudades (Toledo y Sevilla), los soberanos relacionados, la genealogía y los instrumentos memoralísticos.

\section{TOLEDO Y WAMBA: “CUEDAN QUE YAZE Ý ENTERRADO"19}

Como narra la Estoria de España, Wamba fue envenenado por un rival (Ervigio) y pierde la memoria (E1, 185v). El enfermo está alojado en un monasterio, donde muere: "en la villa que dizen Panpliga. e dizen que yentes e cuedan que yaze ý enterrado." (E1, 186r). Desde el punto de vista memorialístico, esta precaria transmisión oral es deficiente, ya que el rey carece de una distinción conmemorativa adecuada: se dice que está enterrado en el monasterio sin mencionarse ninguna necrología ni inscripción. Alfonso remedia este desiderátum de manera concreta, creando una memoria explícita en el interés de una conexión dinástica, cuando en 1274 ordena la excavación de los huesos de Wamba del cementerio de Pampliega y su traslado a Toledo. Alfonso completa así un compromiso que su padre no había logrado cumplir en 1232, y que él mismo tampoco pudo llevar a cabo con éxito en 1254, inmediatamente después de subir al trono (cf. Lafont, 2010, p. 55). La falta de reverencia y de homenaje adecuado son la clave del argumento alfonsino: "Los documentos de la época recogen que el monarca aseguró que "en el lugar no había monasterio ni iglesia como le convenía”." (Diario de León, 17 de julio de 2017). Además, Alfonso pretendía honrar la memoria de Wamba, "that great Visigoth king, a model of good government, secular and religious (he divided the 
parishes) and of virtues" (Martínez, 2010, p. 197). Se puede suponer que Alfonso quería establecer una conexión dinástica en el sentido de una sucesión de reyes, ya que en la misma iglesia de Santa Leocadia del Alcázar en Toledo estaba enterrado Recesvinto, predecesor de Wamba (Izquierdo Benito, 2001, p. 233). Incluso si no está científicamente probado de manera concluyente si la inscripción en esta iglesia -que, según la documentación en un relato de viaje, ${ }^{20}$ enumeraba tanto la designación "rex" como las fechas del reinado, pero ninguna narrativa sobre Wamba, sino exclusiva y explícitamente la narrativa alfonsí ("Transferido del monasterio por Alfonso X" $)^{21}$ - se originó de hecho en la época del Rey Sabio, el mero hecho del traslado ordenado por Alfonso hace evidente la aplicación estratégica de la memoria política con miras a la conformación de su monarquía. El rey de Castilla crea un lugar concreto de memoria, que incrementa la importancia de Toledo como ciudad, que, "in Visigothic times was the head of Spain and where in the past the emperors were crowned". ${ }^{22}$ Este propósito formaba parte, tal vez, de un proyecto más amplio, como sugiere Izquierdo Benito: “¿Pretendía Alfonso X convertir esta iglesia en un panteón de la monarquía visigoda?" (2001, p. 234) En este sentido, la recuperación de los restos del rey Wamba, junto con la inscripción conmemorativa, correspondería a la importancia dada a los reyes visigodos en la Estoria de España como legitimación dinástico-política así como con respecto a su proyecto del Fecho del Imperio.

\section{Sevilla, Fernando y la agenda de memoria genealógica alfonsí}

Sin embargo, no hubo panteón real en la Castilla medieval (Rucquoi, 1992, p. 74), debido, aparentemente, a la idea de que los reyes castellanos "se sitúan por encima de su Iglesia, no la necesitan para organizar su muerte (...) y menos aún para promover una especie de culto a la continuidad dinástica.” (Rucquoi, 1992, p. 75). De acuerdo con este principio, Alfonso organiza esta "continuidad dinástica" él mismo, utilizando el potencial de los instrumentos de memoria arriba analizados. Esta intención se hace evidente en el momento de la transferencia del poder a él, específicamente con motivo del deceso de su padre Fernando, que inicialmente fue enterrado inmediatamente después de su muerte en una simple tumba en la catedral de Sevilla. Pero considerando la importancia de crear la memoria de manera estratégica con vistas a ilustrar una determinada ideología política, Alfonso concibe sus propios lugares de memoria sepulcrales, tanto con vistas al pasado para sus predecesores, como al futuro para sí mismo. Manda construir un monumento funerario más digno para su padre, de acuerdo con un diseño memorialístico que iba a plasmarse en la (antigua) Capilla Real de la catedral de Sevilla. Una vez más, la fijación por escrito es el medio elegido por Alfonso "consciente del poder evocador de la palabra escrita” (Fernández Fernández, 2012, p. 137) para asegurar la narrativa de poder de su dinastía real para toda la eternidad. La inscripción en memoria de su padre dice:

Aquí yaze el rey muy ondrado don Ferrando (...) el que conquiso toda España (...) e el que más temié a Dios e el que más le fazía servicio e el que quebrantó e destruyó a todos sus enemigos (...) e conquiso la cibdat de Sevilla, que es cabeça de toda Epaña (...). (Fernández Fernández, 2012, p. 137)

En esta lápida conmemorativa en Sevilla, el mismo epitafio se escribe en árabe, hebreo, latín y castellano. ${ }^{23}$ Palabras que "sin lugar a dudas serían repetidas una y otra vez en las ceremonias celebradas en honor de Fernando III construyendo un ideal regio en la memoria colectiva de los habitantes de Sevilla." (Fernández Fernández, 2012, p. 137). Según el empleo de los varios instrumentos memorialísticos explayados anteriormente, la combinación de la repetición retórica y performativa con la visualización en un lugar central, el sitio sepulcral, determina este como lugar de memoria. De esta manera Alfonso muestra explícitamente sus intenciones propagandísticas, así como su firme deseo de perpetuar la memoria de su padre dentro y fuera de las fronteras castellanas (Fernández Fernández, 2012, p. 138). La intención hegemónica con la que Alfonso impone su poder autoritativo sobre los distintos idiomas también resulta evidente. En cuanto al contenido y a la conmemoración, se establece la siguiente narrativa de poder para Fernando, como, por consiguiente, también para Alfonso, Sevilla y “toda España”: (re)conquista, reinado, Dios. O, como proclama 
la inscripción sobre la puerta de la ciudad en Calila e Dimna: "Et encomendarse a Dios e meter su fazienda en sus manos e atender su juizio faze al rey que perdió su reino, fázelo cobrar e tornarlo en mejor estado que nunca fuese" (Döhla, 2009, B, p. 452).

\section{ConcLUSIÓN}

En Calila e Dimna, la historia mencionada constituye la ficcionalización de un acto de creación de memoria, en el marco concreto de una transición de poder. Teniendo en cuenta el origen árabe de este espejo de príncipes y su importancia para la lengua castellana, ${ }^{24}$ en cuanto muestra del fenómeno designado por Peter Burke como "Receiving Ideas creatively" (2009, p. 93), la inscripción ficticia en combinación con otros elementos narrativos resultó ser un instrumento decisivo para la creación de lugares de memoria. La escritura y sus soportes respectivos, es decir, la materialización del contenido, corresponden a una "realización" del contenido diseñada para estar presente, ${ }^{25}$ como también hay que entender ciertas inscripciones árabes en el sentido de mantras que "mediante la repetición y el poder evocador de estos términos, (...) tienden a materializarse y a ser eficientes" (Marquer, 2012, párr. 61). El enfoque retórico y el procedimiento de Alfonso tanto en la creación de la Estoria de España como en el diseño de los lugares reales, muestran su alta comprensión de las funciones políticas de tales lugares de memoria, especialmente a través de las inscripciones. Las inscripciones estudiadas muestran la importancia de la escritura y, en particular, del uso del castellano con vistas a los aspectos semánticos de poder y señorío. En este sentido, el léxico utilizado en Calila e Dimna, que fue traducido ya en 1251, es decir, antes de la creación de la Estoria de España, resultó ser un revelador referente de las inscripciones en la Estoria de España. Estas inscripciones son portadoras de las narrativas señoriales como del poder y sirven para crear una memoria colectiva. ${ }^{26}$ Esta puede ser intensificada por la repetición, la ritualización, la visualización, la presentificación (Wenzel, 1993, p. 69) y, por lo tanto, tiene un efecto en el presente, pero también para el futuro.

Funcionalmente y en términos de contenido, todas las inscripciones ficticias y reales examinadas aquí tienen en común la permanencia deseada, la "eternidad”. La memoria debe ser guardada, "congelada”, según Jan Assmann. ${ }^{27}$ En la Estoria de España, la función memorialística de las inscripciones es doblada por su contextualización narrativa y su elaboración retórica. Una innovación con respecto a sus predecesores directos es el énfasis en el diseño de las inscripciones en la Estoria de España, ya que se pueden convertir en los propios títulos de los capítulos, por ejemplo. Además, las inscripciones se perciben ópticamente -también son resaltadas en el texto, llamando la atención-, lo que corresponde al procedimiento en Calila e Dimna de resaltar la inscripción de maneras diferentes en el texto. En la Estoria de España, la importancia de la visualización encaja tanto en el ámbito cortesano como en el ámbito urbano público en la Edad Media:

Sehen ist nicht bloß ein physikalisches Sehen, sondern ein kollektives (kulturelles) Sehen, das der Einzelne mit der Übernahme der gültigen Werte und Normen sich aneignet und verinnerlicht. (...) Gesteigert wird dieses Prinzip in Schrift, Bild und Figur. Sie bilden in wesentlichen Anteilen das "kulturelle Gedächntnis" des Hofes. (...) Schrift, Bild und Figur gelten im Mittelalter als Denkmäler lebendiger Erinnerung. (Wenzel, 1993, p. 60s.) ${ }^{28}$

De manera narrativa Alfonso manda fijar su propia actuación genealógica según la intención formulada por Rodríguez: "El pasado, el presente y el futuro se presentan como los eslabones de una cadena de transmisión" (Rodríguez, 2011, p. 293). El mismo rey asume un papel activo con vistas a esta forma de memoria, pues personalmente manda escribir las narraciones memoralísticas cuya función consiste en la transferencia de la genealogía y de los relatos de acciones históricas en una memoria oficial. Estas narraciones y su implementación corresponden a los instrumentos de memoria diseñados en Calila e Dimna en su combinación de una escritura perdurable, "eterna", y de la inscripción que materializa los contenidos. Esta conexión crea lugares de memoria según las categorías de Nora en toda su complejidad, "simples et ambigus, 
naturels et artificiels, immédiatement offerts à l'expérience la plus sensible et, en même temps, relevant de l'élaboration la plus abstraite" (Nora, 1992, p. XXXIV). ${ }^{29}$

El punto de partida de este artículo fue analizar los instrumentos de memoria presentados en Calila $e$ Dimna en el capítulo "Del fijo del rey e del fidalgo e de sus compañeros" con respecto a su función ejemplar para presentar de manera paradigmática relaciones con el proyecto cultural-político alfonsí que permiten rastrear este ámbito específico. Su traducción, encargada por Alfonso mismo, precede cronológicamente a la Estoria de España. La propia Estoria fue escrita no solo bajo la égida, sino con la colaboración de Alfonso (como agente) y aplica métodos de crear lugares de memoria tal y como fueron explayados en Calila e Dimna. En este sentido, Calila e Dimna debe entenderse también como un fondo de instrumentos de memoria. Gracias a la traducción de Calila e Dimna, primera traducción de un texto narrativo en prosa, como hito, Alfonso da un primer paso para acuñar también la lengua española -otra forma de tesoro memorial-, como idioma literario y político, pragmático, aparte de ser lengua administrativa, como demuestra el rico e importante léxico en el contexto de poder, señorío y de la memoria de narrativas señoriales. El uso de la lengua vernácula en la Estoria de España sirve para "la construcción de un discurso histórico que apunta a la fundamentación de un sentimiento comunitario nacional” (Fernández Gallardo, 2004, p. 115). Por ello, la traducción de las inscripciones latinas de Wamba al castellano en la Estoria merecía una atención especial. También el aviso de Hércules a César está escrito en la "lengua de España" que corresponde a la intención de la Estoria de España de integrar, sobre la base de la geografía, es decir, del territorio, también la historia de la antigüedad romana (Fernández Gallardo, 2004, p. 104). El hecho de que el protagonismo de César con vistas a la fundación de Sevilla se basa en la adaptación de fuentes árabes demuestra las interconexiones transculturales. Los dos aspectos juntos, la participación auctorial/creativa de Alfonso, y el uso del castellano para este texto historiográfico, deben entenderse como "nuevas estrategias comunicativas" (Fernández Gallardo, 2004, p. 119), en las cuales la "escritura” asume un papel clave. El planteamiento teórico de Jan Assmann procura integrar la cultura escrita, por un lado, en el horizonte más amplio de la construcción del tiempo cultural ${ }^{30}$ y, por otro lado, incluirla en el concepto de la "formación de identidad colectiva" o imaginación política (Assmann, 1992, p. 25). Estas mismas coordenadas corresponden al proyecto de Alfonso: los lugares de memoria, con su característica interacción entre identidad política e imaginación cultural, debían contribuir a la creación de una memoria colectiva en el interés de su reinado. La historia de la transmisión de Calila e Dimna igualmente sirve como una genealogía de los grandes gobernantes que contribuyen a ella, es decir, como legitimación a través del saber y de la memoria de los respectivos gobernantes. Por lo tanto, Calila e Dimna no solamente contribuye a la creación de lugares de memoria, sino que es en sí mismo un instrumento de memoria. La noción de que los orígenes árabes del Kalìla waDimna son influyentes igualmente a este respecto es confirmada por la consideración de Daniel Panateri "sobre el procedimiento alfonsí de establecer un discurso nuevo prescindente de sus fuentes a través de su recomposición dentro de su armado argumental que obliga a pensar ese discurso como algo distinto a sus partes componentes" (2019, p. 241). En este sentido, el análisis de la memoria funcional y de la epigrafía en contextos narrativos resultó instructivo. Especialmente las ya mencionadas nuevas estrategias comunicativas así como el papel clave de la "escritura" en su complejidad para Alfonso pueden entenderse de esta manera. En la cultura monárquica de Alfonso, la "escritura” asume así la función principal en todas las formas de memoria funcional, tanto con vistas a los lugares de memoria como en relación con la memoria colectiva buscada. El "guardar" y "tener a disposición" del objeto de escritura en el presente tiene un carácter performativo y sirve para asegurar el futuro transmitiendo el contenido escrito de manera normativa. O, como se dice en Calila e Dimna: "et que lo ayuntase a un libro entero por tal que lo él tomase por castigo para sí mismo et que lo lançaría en sus armarios et que lo dexaría por heredat a los reyes que después d'él veniesen.” (Döhla, 2009, B, p. 124). La estrategia particular de Alfonso X consiste en crear su propia memoria mediante una empresa literaria que comprende inscripciones, traducciones, libros comisionados o escritos por él mismo. 
En este sentido, el Rey Sabio se convierte en la epítome de la definición teórica de la memoria como “construcción del tiempo cultural”, también, y especialmente, desde un punto de vista político.

\section{ReFERENCIAS}

Assmann, A. (1993). Zur Metaphorik der Erinnerung. En A. Assmann y D. Harth (Eds.), Mnemosyne. Formen und Funktionen der kulturellen Erinnerung (pp. 13-35). Francfort d. M.: Fischer.

Assmann, A. (1999). Erinnerungsräume: Formen und Wandlungen des kulturellen Gedächtnisses. Múnich: C. H Beck. Assmann, A. (2013). Cultural Memory and Western Civilization. Functions, Media, Archives ( $2^{\circ}$ ed.; $1^{\circ}$ edición 2011) [Título de la portada del libro de la $2^{\circ}$ ed.: Cultural Memory and Western Civilization. Arts of Memory]. Nueva York [sic]: Cambridge University Press.

Assmann, J. (1992). Das kulturelle Gedächtnis: Schrift, Erinnerung und politische Identität in frühen Hochkulturen. Múnich: C. H Beck.

Burke, P. (2009). Cultural Hybridity. Cambridge: Polity.

Cómez Ramos, R. (2010/2011). El urbanismo alfonsí. Alcanate, 7, 43-101. Recuperado de https://www.eea.csic.es/w p-content/uploads/2016/01/urbanismo-alfonsi-rafael-comez.pdf

Cómez Ramos, R. (2020). El urbanismo en la época de Alfonso X el Sabio. Ars Mediaevalis, 4. Aguilar de Campoo: Fundación Santa María la Real Centro de Estudios del Románico.

Diario de León (17 de julio de 2017). El pueblo de Pampliega pide a la Casa Real los huesos del rey Wamba. Recuperado de https://www.diariodeleon.es/content/print/pueblo-pampliega-pide-casa-real-huesos-rey-wam $\mathrm{ba} / 201707170400011697018$

Döhla, H.-J. (2009). El libro de Calila e Dimna (1251). Nueva edición y estudio crítico de los dos manuscritos castellanos. Zaragoza: Instituto de Estudios Islámicos y del Oriente Próximo.

Drews, W. (2014). Herrschergedenken bei Karolingern und Abbasiden. En S. Scholz, G. Schwedler y K. Sprenger (Eds.), Damnatio in Memoria. Deformation und Gegenkonstruktion in der Geschichte (pp. 243-263). Colonia / Weimar / Viena: Böhlau.

Fernández Fernández, F. (2012). "Muy noble, et mucho alto et mucho honrado". La construcción de la imagen de Fernando III. En C. de Ayala y M. Ríos, Fernando III. Tiempo de Cruzada (pp. 137-174). México-Madrid: UNAM-Sílex.

Fernández Gallardo, L. (2004). De Lucas de Tuy a Alfonso el Sabio: idea de la historia y proyecto historiográfico. Revista de poética medieval, 12, 53-119. Recuperado de https://core.ac.uk/download/pdf/58904982.pdf

Fernández-Ordoñez, I. (2009). Las "Estorias" de Alfonso el Sabio, Biblioteca Virtual Miguel de Cervantes; Edición digital de la edición de Madrid, Istmo, 1992. Recuperado de http://www.cervantesvirtual.com/obra/las-estori as-de-alfonso-el-sabio-0/

Gründler, B. (2018). Kalīla wa-Dimna: A Unique Work of World Literature. En V. M. Lepper y S. A. Sabea (Eds.), Arab and German Tales. Transcending Cultures (pp. 67-68). Berlín: Kadmos.

Herbers, K. (2017). Herrschaftsnachfolge auf der Iberischen Halbinsel. Recht - Pragmatik - Symbolik. En M. Becher (Ed.), Die mittelalterliche Thronfolge im europäischen Vergleich (pp. 231-252). Vorträge und Forschungen 84. Ostfildern: Thorbecke.

Izquierdo Benito, R. (2001). Alfonso X el Sabio, ¿Primer arqueólogo medievalista? Historia, instituciones, documentos, $28,231-240$.

Kristó-Nagy, I. T. (2013). Lapensée d'Ibn al-Muqaffac. Un "agent double" dans le mondepersan et arabe. Studia Arabica XIX. Versailles: Éditions de Paris.

Lacarra, M. J. (1979). Cuentística medieval en España: los orígenes. Zaragoza: Libros Pórtico.

Lafont Mateo, G. (2010). Pampliega, Torrepadierne y Santiuste. Mil años de Historia. Siglos VII al XVII. Pamplona: Germán Lafont Mateo. 
Laguna Paúl, T. (2009). El imperio y la corona de Castilla: la visita a la Capilla de los Reyes de Sevilla en 1500. En M. C. Cosmen, M. V. Herráez Ortega y M. Pellón Gómez-Calcerrada (Eds.), El intercambio artístico entre los reinos hispanos y las cortes europeas en la Baja Edad Media (pp. 217-238). León: Universidad de León.

Las Siete Partidas del rey don Alfonso el Sabio, cotejadas con varios codices antiguos (1807), ed. La Real Academia de la Historia. 3 volúmenes. Madrid: Imprenta Real.

Marquer, J. (2012). Epigrafía y poder: el uso de las inscripciones árabes en el proyecto propagandístico de Pedro I de Castilla (1350-1369).e-Spania, 4. Recuperado de https://doi.org/10.4000/e-spania.21058

Martínez, H. S. (2010). Alfonso X, the Learned. A Biography. Translated by Odile Cisneros. Leiden: Brill.

Martínez Núñez, M. A. (1997). Epigrafía y propagandística almohades. Al Qantara, 18(2), 415-445. https://www.d oi.org/10.3989/alqantara.1997.v18.i2.531

Morales, A. J. (1979). La Capilla Real de Sevilla. Sevilla: Diputación Provincial.

Nora, P. (1992). Entre Mémoire et Histoire. La problématique des lieux. En P. Nora (Ed.), Les lieux de mémoire. Vol. I, La République (pp. XVII-XLII). Paris: Gallimard.

Pahlitzsch, J. (2005). Memoria und Stiftung im Islam. Die Entwicklung des Totengedächtnisses bis zu den Mamluken. En M. Borgolte (Ed.), Stiftungen in Christentum, Judentum und Islam vor der Moderne (pp. 71-94). Berlín: De Gruyter.

Panateri, D. (2019). Elementos árabo-aristotélicos en la obra jurídica alfonsí. Algunas consideraciones. eHumanista, 42, 241-252. Recuperado de https://www.ehumanista.ucsb.edu/sites/default/files/sitefiles/ehumanista/volum e42/ehum42.panateri.fin.pdf

Panateri, D. (2021). Lawmaking and the Normalization of Power during the Middle Ages. The Contribution of the 'Siete Partidas'. En M. Albert, U. Becker y E. Schmidt (Eds.), Alfonso el Sabio y la conceptualización jurídica de la monarquia en las 'Siete Partidas'. Alfonso the Wise and the Juridical Conceptualization of Monarchy in the 'Siete Partidas' (pp. 117-133). Göttingen: V\&R unipress.

Parra Aguilar, L. (2016). Muerte, religiosidad e ideología: el significado del ajuar en los sepulcros de Alfonso X y Sancho IV de Castilla. Hispania Sacra, 68(137), 201-216.

Ricoeur, P. (2003). La memoria, la historia, el olvido, trad. Agustín Neira. Madrid: Trotta.

Rodríguez López, A. (2011). La preciosa transmisión. Memoria y curia regia en Castilla en la primera mitad del siglo del siglo XIII. En P. Martínez Sopena y A. Rodríguez López (Eds.), La construcción medieval de la memoria regia (pp. 293-322). València: Publicacions Universitat de València.

Rucquoi, A. (1992). De los reyes que no son taumaturgos: los fundamentos de la realeza en España. Relaciones, Estudios de Historia y Sociedad, 13(51), 55-100.

Ruíz Souza, J. C. (2012-2013). Alfonso X y el triunfo de la visualización del poder. Alcanate, 8, 221-259.

Sánchez-Prieto Borja, P. (1998). Cómo editar los textos medievales, Madrid: Arco Libros.

Sánchez-Prieto Borja, P. (2011). La edición de textos españoles medievales y clásicos: criterios de presentación gráfica. San Millán: Cilengua.

Sánchez-Prieto Borja, P. (2015). El léxico de la General Estoria de Alfonso X el Sabio. A Lexical Study of Alfonso X the Wise's General Estoria.Anuario de estudios medievales, 45/1, 17-53. https://doi.org/10.3989/aem.2015.45.1.01

Sanmartín, I. (2014). La historia como memoria y la memoria como historia. Tiempo presente, Revista de Historia, 2, 41-52.

Santiago Fernández, J. de (2015). Epigrafía y ciudad en el medievo hispano: inscripciones de origen real y nobiliario. Espacio, Tiempo y Forma, Serie III, Historia Medieval, 28, 515-537. Recuperado de http://dx.doi.org/10.5944 /etfiii.28.2015.14881

Wacks, D. (2007). Framing Iberia: Maqāmāt and Frametale Narratives in Medieval Spain. Leiden: Brill.

Ward, A. (ed.) (2020). Estoria de Espanna Digital v.1.1, University of Birmingham 2020. Recuperado de https://es toria.bham.ac.uk/edition/ 
Wenzel, H. (1993). Imaginatio und Memoria. Medien der Erinnerung im höfischen Mittelalter. En A. Assmann y D. Harth (Eds.), Mnemosyne. Formen und Funktionen der kulturellen Erinnerung (pp. 57-82). Francfort d. M.: Fischer.

\section{Notas}

1 El presente artículo es fruto del proyecto de investigación "Poder y Señorío en la literatura novelística sapiencial castellana (1250-1350)" dirigido por la profesora Mechthild Albert en el marco del grupo de investigación "Poder y Señorío. Configuraciones premodernas en perspectiva transcultural", financiado por la Sociedad Alemana de Investigación (Deutsche Forschungsgemeinschaft, DFG; SFB 1167 "Macht und Herrschaft. Vormoderne Konfigurationen in transkultureller Perspektive"). Una primera versión fue presentada en el marco del panel "La cultura alfonsí como lugar de memoria: Literatura, saberes y poder monárquico”, organizado con motivo del International Medieval Congress (Leeds, 2018).

2 Este análisis utiliza la edición crítica de Döhla (2009), El libro de Calila e Dimna (1251). Nueva edición y estudio crítico de los dos manuscritos castellanos, que incluye los manuscritos A y $\mathrm{B}$. A continuación se citarán las referencias al respectivo manuscrito por medio de las abreviaturas $\mathrm{A}$ o $\mathrm{B}$ antes del número de página.

3 Sobre la importancia del maqāmāt para la literatura española y las implicaciones políticas, véase David Wacks (2007), Framing Iberia: Maqāmāt and Frametale Narratives in Medieval Spain, y María Jesús Lacarra (1979), Cuentistica medieval en España: los origenes.

4 Segunda edición (2013) de la primera y revisada traducción al inglés (2011) de Aleida Assmann (1999), Erinnerungsräume: Formen und Wandlungen des kulturellen Gedächtnisses. Múnich: C. H Beck.

5 Las citas de la edición crítica de Döhla como las de otros textos medievales son regularizadas en aras de la coherencia gráfica y editorial según los manuales de Pedro Sánchez-Prieto Borja (1998), Cómo editar los textos medievales, y SánchezPrieto Borja, P. (2011), La edición de textos españoles medievales y clásicos: criterios de presentación gráfica.

6 Extracto del epitafio, texto completo en Fernández Fernández (2012, p. 137), que se refiere a la transcripción de Alfredo J. Morales (1979, p. 33). Aquí y en lo siguiente se refiere al manuscrito E1, "rama regia" de la Estoria de España, que está disponible en versión crítica en línea, coordinado por Aengus Ward (ed.), Estoria de Espanna Digital v.1.1, Birmingham 2020, https://blog.bham.ac.uk/estoriadigital/. E1 es el único códice del siglo XIII de la Estoria procedente del scriptorium de Alfonso X que contiene la primera redacción de la Estoria de España (hacia 1270-1274), según la descripción codiológica de Inés Fernández-Ordóñez (https://blog.bham.ac.uk/estoriadigital/manuscripts-of-the-estor ia-de-espanna/).

7 Términos traducidos por Agustín Neira de los términos franceses de Ricoeur, su terminología basándose a su vez en su consideración crítica de una traducción francesa, anotada en inglés de los textos aristotélicos (Ricoeur, 2003, p. 33, nota 13).

8 Döhla, 2009, A, p. 441, donde se especifica también el nombre de la ciudad: “su cibdad que dezian Matrofil”. En B, p. 441, queda sin referencia concreta: "la cibdat suya".

9 Ver p. ej. Kristó-Nagy (2013), La pensée d'Ibn al-Muqaffac , p. 104 y p. 244. Con respecto a Alfonso X ver p. ej. Rafael Cómez Ramos (2020 y 2010/2011) acerca de las características propias del urbanismo alfonsí y la importancia de su política en el desarrollo urbanístico.

10 ["La memoria está arraigada en lo concreto, en el espacio, el gesto, la imagen y el objeto". Traducción por la autora].

11 Estoria de España, E1, 182v, Transcription (https://estoria.bham.ac.uk/edition/). Se citará siempre en la versión de “Transcription" según la edición crítica, es decir, sin los caracteres editoriales o especiales relacionados con la disposición del manuscrito. Las citas son regularizadas como se indica en la nota 5.

12 Santiago Fernández, 2015, p. 524, en referencia a Rodríguez y Souto, 2000, p. 209.

13 Esta inscripción se encuentra también en el manuscrito E1, $5 \mathrm{r}$.

14 Fernández-Ordoñez, cita de al-Bakrï, Geografía de España, p. 31.

15 ["El pasado que se solidifica e interioriza en la historia fundacional es un mito, completamente independiente de si es ficticio o real." Traducción por la autora].

16 Extracto del epitafio, texto completo en Fernández Fernández (2012, p. 137). Se refiere a la transcripción de A. J. Morales (1979, p. 33).

17 Drews, 2014, p. 256: “[ihr] wesentliches symbolisches Kapital, die Verwandtschaft mit dem Propheten”.

18 Drews, 2014, p. 256. La importancia del libro como lugar de recuerdo, tal como lo representa la historia de la adquisición de Calila e Dimna, así como la importancia resultante de la producción de libros en el taller alfonsí no pueden ser elaboradas con más detalle aquí. Queda claro que la historia de la transmisión de Calila e Dimna, de un gran gobernante sabio a otro, debe clasificarse como una cadena legitimadora, por lo que la puesta a disposición a través de la traducción y 
la posesión de estos conocimientos transmitidos / la sabiduría sirven como prueba de idoneidad regia. Alfonso se inscribe explícitamente en esta cadena por medio de un exit genealógico-dinástico (Döhla, 2009, B, p. 492s.).

19 E1, 186r, citado según la nota 11.

20 Izquierdo Benito (2001, p. 234, nota 10) se refiere como única fuente a Alfonso Ponz, Viage de España, Madrid 1787, tomo primero, 190-191 (edición facsímil de Ediciones Atlas, Madrid, 1972).

21 "En tumulus jacet Rex inclitus Wamba. Regnum contempsit anno DCLXXX. Monachus obiit anno DCLXXXVII. E Coenobio translatus ab Alfonso X."

22 Con estas palabras Salvador Martínez (2010, p. 197) cita de un diploma de Alfonso. Sobre la destacada importancia de Toledo para los visigodos en términos de simbolismo y memoria, cf. Herbers (2017, p. 252).

23 La lápida forma parte de la extensa puesta en escena y representación de la memoria funeraria genealógica alfonsina en Sevilla. Alfonso hace prospectivamente instrucciones testamentarias en las que determina el lugar de su entierro, “junto a sus padres" (cf. Parra Aguilar, 2016, p. 203). Todo el diseño de la capilla está orientado genealógicamente y contribuye a la legitimación real, como también se ha explicado con respecto a las inscripciones: "Toda la disposición de esta capilla, realizada por encargo de Alfonso X antes de 1279, (...) pretendía (...) mostrar a los súbditos las realidades y aspiraciones de la monarquía que, en pleno proceso de autoafirmación, tenían como prototipo de monarca a Fernando III" (Laguna Paúl, 2009, p. 217). La relación con la Estoria de España también es evidente con respecto a la visualización: "La escenografía de las esculturas de los reyes entronizados (Fernando III, Beatriz de Suabia y Alfonso X) en la capilla real sevillana debería ponerse en relación con la leyenda que hacia 1265 se elabora respecto al Cid Campeador. Nos referimos a la imagen que se recoge en la propia Estoria de España respecto a la disposición del cadáver del Cid en San Pedro de Cardeña, como si de un nuevo Carlomagno se tratase." (Ruíz Souza, 2012-2013, p. 242s.). El objetivo es la legitimación a través de la continuidad para el futuro: "Las sepulturas de los reyes de Castilla y León nos muestran cómo los monarcas extendían su poder aún en la muerte." (Parra Aguilar, 2016, p. 201).

24 Calia e Dimna se considera la cuna de algunos arabismos; además, como espejo de príncipes y texto sapiencial en forma de prosa narrativa, es revelador en cuanto a los ámbitos referenciales tanto en lo semántico como en lo conceptual (cf. sobre la importancia de los ámbitos referenciales Pedro Sánchez-Prieto Borja, 2015, p. 22s.).

25 Un efecto comparable al modo de actuación de la materialidad con vistas a los códices de las Siete Partidas y "the physical exhibition of the juridical manifestation of royal power” explayados por Panateri (2021, p. 125). Así, las narrativas de poder son omnipresentes e impactantes.

26 Aunque, según Assmann (1992, p. 121), Maurice Halbwachs distingue con claridad entre "collective memory" y "historiography." Pero precisamente esta distinción entre memoria colectiva e historia parece obsoleta con vistas al procedimiento alfonsino, pues Alfonso igualmente funcionaliza la historiografía de manera apta.

27 Inscripciones como quietivos, en contraposición a incentivos: "Hier geht es darum, Wandel einzufrieren. Der Sinn, der hier erinnert wird, liegt (...) in der Kontinuität, nicht in Bruch, Umschwung und Veränderung" (Assmann, 1992, p. 70). ["El punto aquí es congelar el cambio. El significado que se recuerda aquí reside (...) en la continuidad, no en la ruptura, el giro y el cambio.” Traducción por la autora].

28 "[El] ver no es un mero ver físico, sino un ver colectivo (cultural), que el individuo se apropia e interioriza adoptando los valores y normas válidos. (...) Este principio se intensifica en la escritura, la imagen y la figura. Estas forman en partes esenciales la "memoria cultural" de la corte. (...) La escritura, la imagen y la figura son consideradas en la Edad Media como monumentos de la memoria viva.” Traducción por la autora].

29 ["simple y ambiguo, natural y artificial, inmediatamente disponible para la experiencia más sensible y, al mismo tiempo, de la elaboración más abstracta”. Traducción por la autora].

30 Jan Assmann (1992, p. 25) se refiere al origen del concepto de “construcción del tiempo cultural” de Aleida Assmann. 